\title{
US health care reform: a work in progress
}

\author{
Sean D. Sullivan
}

Published online: 27 February 2010

(C) Springer-Verlag 2010

In January, the largest US health insurer, Wellpoint, announced that it would raise annual premiums by between 30 and $39 \%$ in 2010 for individual members in its Anthem Blue Cross plan of California. The rate increase comes just days after it announced earnings of $\$ 4.7$ billion in 2009 . The health insurer claims the bad economy and rising health care costs are to blame for the rate increases. The largest rate increase will be felt in the individual insurance markets-that is, for customers who purchase insurance directly rather than through an employer. Many of the 800,000 individual members in the California subsidiary will not be able to afford these increases and will likely join the 45 million Americans without health care coverage. Such stories give rich texture to the ongoing health care debate in the US.

The current legislation on health care reform in the US attempts a comprehensive package of reforms. After staunch debate and substantial political maneuvering over the past 6 months, what has emerged from the US Congress are two health care bills that frame reform in terms of expanding coverage to those without insurance, regulatory reforms for the private health insurance markets and various cost control measures for Medicare and Medicaid. For those wishing a to see a detailed explanation of the reforms, the Kaiser Family Foundation provides a side-byside comparison of both the House and Senate version on their website [1].

The main reforms are intended to expand access through compulsory insurance coverage mandates on individuals and businesses as well as a massive expansion of the

S. D. Sullivan $(\bowtie)$

Pharmaceutical Outcomes Research and Policy Program, University of Washington, Seattle, WA 98195, USA

e-mail: sdsull@u.washington.edu federal/state financed Medicaid and Child Health Insurance Programs. The intent of these expansions is to reduce the number of uninsured. Individuals (US citizens and legal residents) without coverage will be required to purchase subsidized insurance through an insurance exchange set up ostensibly to make coverage more affordable. A particularly difficult debate is whether or not the federal government should offer a publicly operated insurance option to compete with private insurance carriers in the insurance exchange. This provision has generated substantial political and ideological debate and has not been resolved.

Currently, less than $35 \%$ of small businesses offer health insurance coverage for their employees. Businesses with more than 50 employees will now be required to offer coverage or face a fine. Qualified businesses can apply for significant premium subsidies and favorable tax treatments if they offer health insurance coverage to employees. Perhaps less controversial for the American public are planned reforms for the health insurance industry. The legislation calls for elimination of industry practices that are unpopular, such as the pre-existing condition clause and lifetime insurance limits. These benefit restrictions effectively reduce future cost exposure for insurance companies to individuals seeking insurance with pre-existing medical conditions or for those who develop a catastrophic illness after coverage and require expensive treatments. The insurance industry opposes these reforms.

Finally, one of the most debated elements of the reform package involves structural and provider reimbursement changes to the Medicare program. Historically, Medicare has enjoyed widespread support from the American public. Americans value the health care security provided by Medicare. Today, the Medicare, Medicaid and Social Security programs consume $41 \%$ of federal spending, and projections suggest that these programs will exceed $60 \%$ of 
federal spending by 2030 when all of the post-World War II baby boom generation reaches 65 . Reformers fully understand the fiscal imperative to modify the federal health care programs in order to bring revenue in line with expense. The current legislation proposes creation of an independent commission to advise the Medicare program on cost management and quality improvement strategies to improve efficiency and rein in spending. Some believe this commission may be a precursor to formal health technology assessment for Medicare. This commission has been labeled a 'death panel' by former vice-presidential candidate, Sarah Palin.

The legislation is stalled after the surprise election of a Massachusetts Republican to replace long-standing Senate health reform leader and Democrat Edward Kennedy.
The election of a Republican in a solidly Democratic state has given pause to those in Congress who support reform for fear of voter backlash in their own jurisdictions during the coming mid-term elections. President Obama has asked the Congress to act quickly on health care reform, pressing both political parties to rejoin the negotiations. Tough choices and clear leadership are needed to bring the reforms to reality.

\section{Reference}

1. Kaiser Family Foundation. http://www.kff.org/healthreform/ sidebyside.cfm. Accessed 9 Feb, 2010 